\title{
Broad bean cultivars increase extrafloral nectary numbers, but not extrafloral nectar, in response to leaf damage
}

\author{
Edward B. Mondor*, Carl N. Keiser, Dustin E. Pendarvis, Morgan N. Vaughn \\ Department of Biology, Georgia Southern University, Statesboro, USA; ${ }^{*}$ Corresponding Author: emondor@georgiasouthern.edu
}

Received 5 October 2012; revised 16 November 2012; accepted 27 November 2012

\begin{abstract}
Phenotypic plasticity allows organisms to maximize fitness, by optimizing the expression of costly defensive traits. Broad bean, Vicia faba $L$. "Broad Windsor", produces increased numbers of extrafloral nectaries (EFNs) in response to leaf damage to attract mutualistic partners and reduce herbivory. It is currently unknown, however, whether EFN induction is cultivar-specific or is a more general phenomenon. It has also not been determined whether broad beans increase nectar secretion rates in conjunction with EFN induction. We hypothesized that: a) as all broad beans have conspicuous EFNs, all cultivars should produce additional EFNs in response to leaf damage, and b) overall nectar secretion rates should increase with EFN numbers, to attract additional mutualists. We tested our hypothesis by subjecting three broad bean cultivars, Vicia faba L. "Broad Windsor", "Stereo", and "Witkiem" to mechanical leaf damage. The degree of change in plant traits associated with growth, in addition to EFN induction, was assessed 1 week after leaf damage. Extrafloral nectar volumes were also assessed, every 24 hours, pre- and post-leaf damage. We confirmed our first, but rejected our second, hypothesis. All cultivars produced additional EFNs, but none increased extrafloral nectar volumes, when experiencing leaf damage. Further experimentation is required to determine if energetic tradeoffs limit multiple forms of defense (i.e., EFN vs. nectar induction), or if this alternative strategy is adaptive for attracting and retaining mutualists. Understanding the costs and benefits of EFN vs. nectar induction will provide insight into the evolution of defensive mutualisms between plants and predatory arthropods.
\end{abstract}

Keywords: Broad Bean; Defense; Extrafloral
Nectar; Extrafloral Nectary; Herbivory; Inducible Defense; Mutualism; Phenotypic Plasticity; Vicia faba L.

\section{INTRODUCTION}

When herbivory or predation risk increases, some plants and animals have the ability to alter their phenoltype to decrease risk of further attack [1-4]. This plasticity enables organisms to express costly traits when required, and to reduce or eliminate these costs when such phenotypic expression is not necessary [5-7]. Inducible defenses, such as altered phenotypic expression, are adaptive when risk of attack is unpredictable and inferquent $[2,8,9]$. Conversely, if herbivory or predation is predictable and recurrent, constitutive defenses would be selected for, as the costs of developing and expressing defensive traits would be offset by the benefits of increased survival and (or) reproduction $[2,8,9]$. Irregardless of the modality, organisms optimize defensive traits to maximize fitness $[10,11]$.

Defensive mutualisms, whereby one organism produces rewards to attract other organisms for protection, have been commonly observed [12-15]. In plants, over 93 families produce extrafloral nectaries (EFNs) [16], sugar producing structures outside of floral structures, which attract predatory arthropods, most commonly ants [14,17-20], but other insects as well [21,22]. While the evolution of EFNs has been debated [16,23,24], these structures frequently facilitate defensive mutualistic interactions between plants and natural enemies of the plant's herbivores [18,25-29]. Increased plant survival and (or) reproduction has been noted when predatory insects visit EFNs $[19,20,27,28]$. Increased plant fitness could maintain the expression of these sugar-producing organs, despite the initial selective pressures resulting in their evolution.

To facilitate the attraction and (or) retention of mutualists, many plants increase nectar secretion rates from existing EFNs in response to leaf damage [27,28,30,31]. 
More rarely, some species, such as broad bean Vicia faba L. [32-34] and sweet cherry Prunus avium L. [35], produce additional EFNs when damaged. Located on the leaf stipules at the base of the petioles, broad bean EFNs range in degree of purple coloration creating a conspicuous visual display (purple EFNs on a light green stipule-[32]), in contrast to an inconspicuous display (green EFNs on green leaf or stem tissue) found on many other plant species [29,36,37]. Herbivore-specific elicitors are not required for [32,33], and both abiotic and biotic factors influence $[33,34,38]$, EFN induction in broad bean plants.

Thus far, EFN phenotypic plasticity has been examined in only two cultivated varieties (cultivar) of broad bean, V. faba "Broad Windsor" [32,33,38] and "Hangdown" [34]. It is not known whether other cultivars produce additional EFNs in response to herbivory (i.e., if induction is a cultivar-specific response or a more general phenomenon in this species). To our knowledge, all plants of this species produce conspicuous EFNs [39,40], thus selection should promote similar induction responses in all varieties. It is also unknown whether broad bean plants simultaneously alter extrafloral nectar secretion rates. Though increased extrafloral nectar secretion rates are commonly observed in other plant species $[27,28,36,41]$, other species have not been shown to increase EFN numbers. Thus, it is unknown if most broad bean cultivars increase EFN numbers, nectar secretion rates, or both.

We hypothesize that EFN induction in broad bean is not cultivar-specific, but rather, all cultivars will produce additional EFNs in response to leaf damage. As all broad bean cultivars have conspicuous EFNs [39,40], it would be adaptive to produce a larger visual display to attract additional defensive mutualistic partners (i.e., predatory arthropods-[42]). We also hypothesize that plants will increase extrafloral nectar secretion rates, in response to leaf damage. If plants increase per-plant nectar production, they are more likely to attract and retain mutualistic partners [14,17-22]. Here, we test these two hypotheses by assessing the ability of three broad bean, $V$. faba, cultivars to produce additional EFNs and (or) extrafloral nectar over 1 week following mechanical leaf damage.

\section{MATERIALS AND METHODS}

\subsection{Plants}

Broad bean, $V$. faba, seeds were individually planted in Fafard 3B potting mix (Conrad Fafard Inc., Agawam, MA) in 1L round, black, plastic pots. Three cultivars were used for the experiments: Broad Windsor, Stereo, and Witkiem. Plants were watered daily, top-dressed with Osmocote 14-14-14 N-P-K slow-release fertilizer (ScottsSierra Horticultural Products, Marysville, $\mathrm{OH}$ ) prior to seedling emergence, and grown under greenhouse condi- tions $\left(13^{\circ} \mathrm{C}-6^{\circ} \mathrm{C}, 22 \%-45 \% \mathrm{rh}\right.$, natural lighting $)$ in a computer-generated random order using JMP 8.0 [43], to control for any differential lighting effects.

\subsection{Is EFN Induction, in Response to Leaf Damage, Cultivar Specific?}

When plants were $15 \mathrm{~cm}$ tall with 4 true leaves (averaged across all experiments), we recorded initial plant traits: plant height, number of partially expanded leaves, number of fully expanded leaves, and number of EFNs. Presence of EFNs was determined using a magnifying glass (Merangue LG807BL; Merangue International Ltd., Markham, ON Canada), as nectaries can differ in degree of purple coloration [33]. After recording these traits, leaf damage treatments were administered. For replicates with leaf damage, the outer one-third of each fully expanded leaf pair was excised using floral scissors. To ensure that compounds were not transferred between plants, the scissors were cleaned with an alcohol swab after excising tissue from each plant.

We used mechanical leaf damage for our treatments because the degree of tissue removal, compared to real herbivory, can be carefully controlled [44]. Plants exhibit similar increases in nectar secretion rates in response to both natural and mechanical leaf damage [27,36]. It is believed that "damage self-recognition" cues resulting from plant tissue damage per se, and not a herbivorespecific elicitor, is the necessary stimulus for these induction responses [45]. Furthermore, in previous studies, mechanical damage clearly increased EFN numbers in $V$. faba [32,33] and P. avium [35].

After assessing initial plant traits, broad beans were allowed to grow for 1 week, at which time plant traits were assessed a second time. Pre-treatment values were subtracted from post-treatment values to quantify the degree of change in each character. Immediately after assessing traits, plant shoots were cut at soil level, roots washed, and both plant parts placed in separate paper bags for drying. Root and shoot portions of each plant were dried for 2 weeks, then weighed to the nearest 0.01 g (Ohaus GT4100 balance; Ohaus Corporation, Pine Brook, NJ, USA).

This experiment was replicated three times. In trials 1 , 2 , and 3, replicate numbers were: Broad Windsor, no leaf damage - 12, 11, 15, leaf damage - 13, 11, 15; Stereo, no leaf damage-10, 8, 8, leaf damage-13, 10, 10; Witkiem, no leaf damage $-5,10,8$, leaf damage $-5,5,4$ respectively. Witkiem replicate numbers were lower than the other cultivars due to low germination rates.

\subsection{Do Nectar Volumes Increase, in Different Cultivars, in Response to Leaf Damage?}

During our third trial, we also assessed extrafloral 
nectar secretion rates. Prior to conducting the leaf damage treatments, we collected and measured total nectar volumes per plant using microcapillary pipets (Kimble Glass Inc, Vineland, NJ, USA). Nectar was removed from each plant 24 hours before treatments (to remove any "standing crop" of nectar), collected immediately prior to leaf damage treatments ("pre-treatment"), and then every 24 hours ( \pm 2 hours) for 4 days after damage ("posttreatment"). Every nectary on a plant was assessed for the presence of nectar, irrespective of whether a droplet was visible. Replicate numbers for this experiment were as previously stated.

\subsection{Statistical Analyses}

To determine if EFN induction was cultivar- and (or) damage-dependent, data were analyzed with a two-way Analysis of Covariance (ANCOVA). By using ANCOVA, a model combining ANOVA and linear regression, it is possible to determine the effects of key, nominal variables, while correcting for variability in and assessing the influence of continuous variables, on a dependent variable. Main factors in the analysis were: cultivar (Broad Windsor vs. Stereo vs. Witkiem) and leaf damage (no vs. yes). Covariates were: change in stem length, change in number of partially expanded leaf pairs, change in number of fully expanded leaf pairs (all 1 week post-leaf damage), dry shoot weight, and dry root weight. Experiment $(1-3)$ was also included as a covariate, to control for differences between trials. The dependent variable was the change in the number of EFNs on each plant, over 1 week.

As shoot weight was highly significant in the previous analysis, and to further assess putative plant defense, an additional one-way ANCOVA was performed. The main factors and covariates were the same as in the EFN induction analysis. The dependent variable, however, was: EFNs per gram of dry shoot weight. This analysis allowed us to assess EFN induction per unit of plant biomass.

Nectar secretion rates, in response to leaf damage, were analyzed with Multivariate Analysis of Variance (MANOVA), "contrast" function. The "contrast" function allowed us to assess changes in nectar secretion across time, with respect to the pre-treatment amounts (i.e., Pretreatment vs. 24 hours post-treatment, Pre-treatment vs. 48 hours post-treatment, etc.). The same independent variables were used as in the previous analysis. Covariates were: stem length, number of partially expanded leaves, number of fully expanded leaves, and number of EFNs (all immediately pre-treatment). Dry shoot and root weights were also included as covariates, to account for overall biomass effects. The dependent variable was total nectar volume (in microliters) per plant. Nectar volume was cube root transformed $\left[\mathrm{x}^{\prime}=\sqrt[3]{\mathrm{x}}\right]$ [47], prior to analysis to normalize the data. For all experimental analyses, statistical calculations were performed using JMP 8.0 [43].

\section{RESULTS}

\subsection{Is EFN Induction, in Response to Leaf Damage, Cultivar Specific?}

All broad bean cultivars tested produced additional EFNs in response to leaf damage. Different cultivars had different induction responses; Broad Windsor produced more EFNs than did Stereo or Witkiem $\left(F_{2.161}=6.75, P=\right.$ $0.0015)$. Plants that suffered leaf damage produced more EFNs than undamaged plants $\left(F_{1.161}=34.44, P<0.0001\right)$, and this effect was consistent across cultivars, as demonstrated by no significant interaction $\left(F_{2.161}=2.43, P=\right.$ 0.092; Figure 1). There was no difference in plant responses between trials $\left(F_{1.161}=1.01, P=0.32\right)$. Extrafloral nectary numbers increased in association with numbers of partially developed $\left(F_{1.161}=3.91, P=0.050\right)$ and fully developed $\left(F_{1.161}=30.70, P<0.0001\right)$ leaf pairs, and dry shoot weights $\left(F_{1.161}=20.92, P=0.0001\right)$. Neither plant heights $\left(F_{1.161}=1.73, P=0.19\right)$ nor dry root weights $\left(F_{1.161}=0.0018, P=0.97\right)$ were associated with EFN induction responses.

As dry shoot weight was a significant covariate in EFN induction, and to provide a better estimate of plant phenotypic expression on tissue defense, EFN induction per gram of dry shoot weight was assessed. Using this standardized metric, Broad Windsor produced more EFNs than did Stereo, with Witkiem showing an intermediate response $\left(F_{2.163}=3.75, P=0.026\right)$. There was still a large effect of leaf damage on induction responses $\left(F_{1.163}\right.$ $=24.41, P<0.0001)$. Like in the previous analysis, there was no significant interaction between cultivar and leaf damage $\left(F_{2.163}=1.17, P=0.31\right.$; Figure 2); damaged

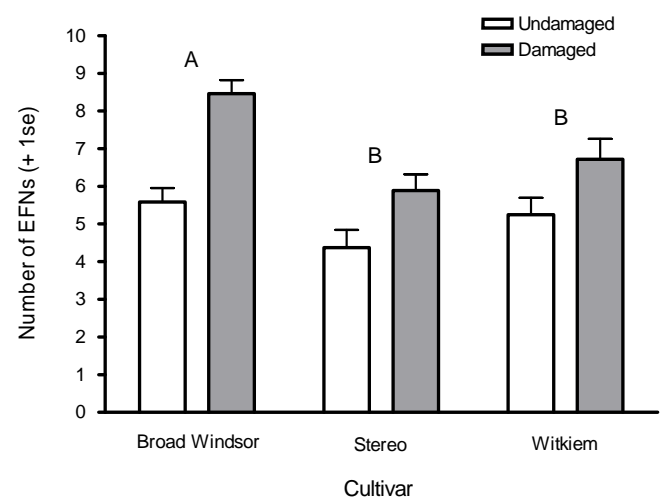

Figure 1. Mean extrafloral nectary (EFN) numbers produced by plants of three broad bean cultivars, $V$. faba, over one week in response to mechanical leaf damage. All cultivars produced more EFNs when damaged. Cultivars with different letters produced different numbers of EFNs overall, Tukey's HSD test $(P \leq 0.05)$. 


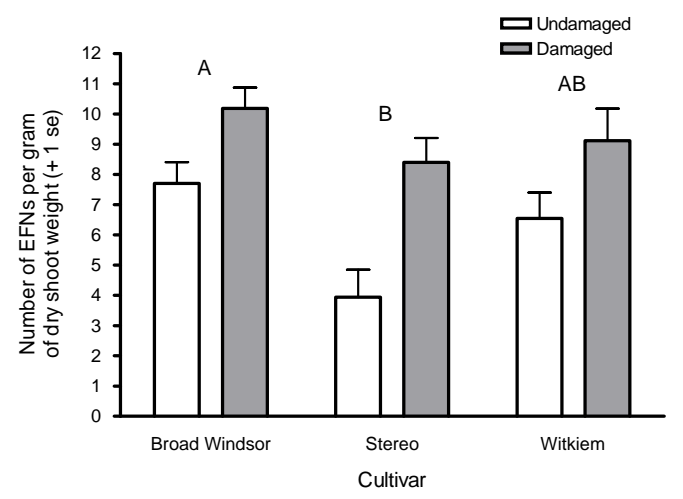

Figure 2. Mean EFN numbers produced by three broad bean cultivars, per gram of dry shoot weight. All cultivars produced more EFNs in response to mechanical leaf damage. Cultivars with different letters produced different numbers of EFNs overall, Tukey's HSD test $(P \leq 0.05)$.

plants always produced more EFNs, irrespective of cultivar. Only two covariates were related to EFN induction responses per unit of biomass: trial $\left(F_{1.163}=27.31, P<\right.$ $0.0001)$ and plant height $\left(F_{1.163}=18.27, P<0.0001\right)$. Plants that grew less in height over 1 week, had larger induction responses. Numbers of partially developed $\left(F_{1.163}=0.0001, P=0.99\right)$, and fully developed $\left(F_{1.163}=\right.$ $1.38, P=0.24$ ) leaf pairs were not reliable predictors of EFN induction responses.

\subsection{Do Nectar Volumes Increase, in Different Cultivars, in Response to Leaf Damage?}

We found, unequivocally, that nectar secretion rates in all three cultivars did not significantly increase in response to leaf damage. Compared to the pre-treatment nectar amounts, post-treatment nectar volumes did not differ among cultivars $\left(F_{8.90}=1.40, P=0.21\right)$ nor did they increase in response to leaf damage $\left(F_{4.45}=2.19, P\right.$ $=0.086)$.

In fact, the non-significant trend was for undamaged plants to have higher nectar secretion rates than damaged plants. There was no interaction between cultivar and leaf damage $\left(F_{8.90}=1.13, P=0.35\right.$; Figure 3$)$. Furthermore, none of the covariates: pre-treatment plant height $\left(F_{4.45}=0.99, P=0.42\right)$, pre-treatment number of partially expanded leaves $\left(F_{4.45}=0.28, P=0.89\right)$, pre-treatment number of fully expanded leaves $\left(F_{4.45}=1.32, P=0.28\right)$, pre-treatment number of EFNs $\left(F_{4.45}=0.25, P=0.91\right)$, dry shoot weight $\left(\mathrm{F}_{4.45}=1.52, P=0.21\right)$, and dry root weight $\left(F_{4.45}=0.72, P=0.59\right)$ were significant.

\section{DISCUSSION}

Plants benefit by producing nutritious rewards to attract and retain mutualistic partners, to increase fitness [14,17-22,25,47]. As extrafloral nectaries (EFNs) and

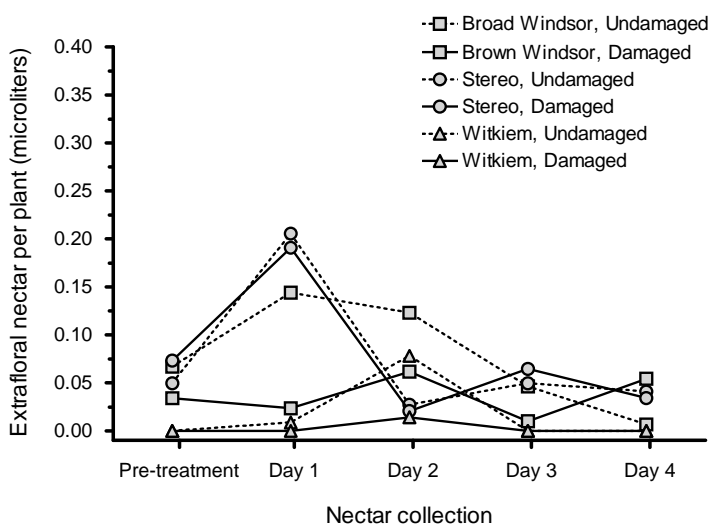

Figure 3. Mean volumes of extrafloral nectar produced, preand post-leaf damage, by three broad bean cultivars. There was no effect of leaf damage on extrafloral nectar secretion rates.

nectar may be costly to produce $[33,48-50]$, phenotypic plasticity allows plants to increase expression only when risk of herbivory increases. Previously, two broad bean cultivars, Vicia faba "Broad Windsor" [32,33] and "Hangdown" [34], were shown to alter EFN numbers in response to leaf damage (though see [38]). Here we tested the hypotheses that, in response to leaf damage: 1) all broad bean cultivars will produce additional EFNs, and 2) plants will also increase nectar secretion rates, to attract additional mutualists. Here, we present data that confirms our first, but rejects our second, hypothesis. Every cultivar produced additional EFNs, though there was no difference in nectar secretion rates, after experiencing leaf damage.

It is clear that EFN induction is a species-wide effect in broad bean plants. Broad Windsor has become the cultivar of choice for experiments on EFN induction $[32,33,38]$, because it is easy to grow, is a large, robust plant, and has easily recognizable EFNs. It is interesting that the largest induction responses occurred in the Broad Windsor cultivar, of all the varieties tested. Some cultivars are more difficult to grow and are less robust (EB Mondor, Georgia Southern University, USA, unpubl. res.). Some researchers have suggested that a more appropriate measure of putative plant defense is looking at EFN induction per unit of leaf and stem tissue, i.e., the actual plant area to be defended [28,51]. When looking at EFN induction per unit of biomass (i.e., per gram of dry shoot weight), the smallest statured cultivar, Stereo, had the largest induction response. Thus, while plant vigor may be correlated with overall EFN numbers, the smallest plants may be the most heavily defended on the basis of EFNs per unit of above-ground biomass.

Most puzzling is why broad bean plants increase EFN numbers, but not nectar secretion rates in response to leaf damage. Many plant species increase extrafloral nectar secretions when damaged [27,28,36,41]. We propose at least three non-mutually exclusive reasons why broad 
bean plants might increase EFNs but not increase nectar secretions. First, plants may not have the resources to increase both EFN numbers and nectar secretion. Plants have finite resources available for growth, defense, and reproduction [52]. Though the overall costs of EFN induction have not yet been assessed, it is resource-dependent [33]. Nectar is also believed to be costly to produce $[49,50]$. Thus, this experiment may demonstrate a classic example of a defensive trade-off; an increase in one defensive trait decreases another [52]. These tradeoffs may be especially prevalent in annual plants, like broad beans, as fitness (seed production) is solely determined in one year, as opposed to perennial plants where fitness is accrued over multiple years [53]. Second, it may be adaptive for plants to distribute the same level of resources over a more widely scattered area. By increasing EFNs, predatory arthropods would be required to search more plant surface area to obtain the same level of nutrients, as opposed to being directed to a specific area to defend [54]. It is postulated that herbivores would be more likely to be discovered and removed from the plant, due to the increased levels of search behavior over the plant surface, thereby further reducing herbivory $[14,17$, 18]. Third, it is possible that this effect has a physiological basis. Compensatory growth may occur in response to leaf damage $[55,56]$, thereby accelerating stipule production prior to leaves unfolding, leading to more EFNs per leaf pair on a plant [33]. A transitory reallocation of resources from defense to growth, underlying this inducible defense, would explain how EFN numbers per leaf pair can change significantly in just a few days [34]. Further experimentation is required to better understand this phenomenon.

The adaptive significance of EFN vs. nectar induction needs to be addressed, in an array of plant species. Understanding the tradeoffs between these two defensive strategies may provide great insight into the selective pressures that mediate defensive mutualisms [31,45,57]. These two defensive strategies may function optimally for different mutualistic partners. For example, ants frequently visit EFNs, and their presence has been linked to increased plant survival and (or) reproduction [17,19,28, 47,58,59]. Many other predatory arthropods, however, are attracted to and feed on EFNs (e.g., predatory coccinellids, parasitic Hymenoptera-[21,22,60-62]). It should be investigated whether plants with conspicuous EFNs have different natural enemy guilds compared to those defending plants with inconspicuous EFNs.

Mutualistic interactions are dynamic associations that are highly dependent on the current ecological conditions $[63,64]$ (though see [65]). Defensive mutualisms between plants and predatory insects are commonly mediated through EFNs and their nutrient-rich secretions $[14,16,18]$. Multiple broad bean cultivars produce addi- tional EFNs in response to leaf damage, but none of these plants increase nectar secretion rates. A better understanding of the cost/benefit tradeoffs between EFNs and nectar [66], in both wild and cultivated plants, will provide great insight into the evolution of plant defense $[1,2,53]$.

\section{ACKNOWLEDGEMENTS}

We thank M. Tremblay and M. Heil for comments on this manuscript. We also thank B. Cantwell, K. Duff, and A. Shepard for laboratory assistance. This work was supported by the Department of Biology and Georgia Southern University.

\section{REFERENCES}

[1] Karban, R. and Baldwin, I.T. (1997) Induced responses to herbivory. University Press of Chicago, Chicago.

[2] Tollrian, R. and Harvell, C.D. (1999) The ecology and evolution of inducible defenses. Princeton University Press, Princeton.

[3] Sultan, S.E. (2000) Phenotypic plasticity for plant development, function, and life-history. Trends in Plants Science, 5, 537-542. doi:10.1016/S1360-1385(00)01797-0

[4] Dewitt, T.J. and Scheiner, S.M. (2004) Phenotypic plasticity: functional and conceptual approaches. Oxford University Press, New York.

[5] West-Eberhard, M.J. (1986) Alternative adaptations, speciation, and phylogeny. Proceedings of the National Academy of Sciences of the USA, 83, 1388-1392. doi:10.1073/pnas.83.5.1388

[6] West-Eberhard M.J. (1989). Phenotypic plasticity and the origins of diversity. Annual Review of Ecology and Systematics, 20, 249-278. doi:10.1146/annurev.es.20.110189.001341

[7] Moran, N.A. (1992). The evolutionary maintenance of alternative phenotypes. The American Naturalist, 139, 971-989. doi:10.1086/285369

[8] Zangerl, A.R. and Rutledge, C.E. (1996) The probability of attack and patterns of constitutive and induced defense: A test of optimal defense theory. American Naturalist, 147, 599-608. doi: $10.1086 / 285868$

[9] Karban, R., Agrawal, A.A. and Mangel, M. (1997). The benefits of induced defenses against herbivores. Ecology, 78, 1351-1355.

doi:10.1890/0012-9658(1997)078[1351:TBOIDA]2.0.CO ;2

[10] Stearns, S.C. (1992). The evolution of life histories. Oxford University Press, Oxford.

[11] Steiner, U.K. and Pfeiffer, T. (2007) Optimizing time and resource allocation trade-offs for investment into morphological and behavioral defense. The American Naturalist, 169, 118-129. doi:10.1086/509939

[12] Boucher, D.H., James, S. and Keeler, K.H. (1982) The ecology of mutualism. Annual Review of Ecology and Systematics, 13, 315-347.

doi:10.1146/annurev.es.13.110182.001531 
[13] Pierce, N.E., Kitching, R.L., Buckley, R.C., Taylor, M.F.J. and Benbow, K. (1987) Costs and benefits of cooperation between the Australian lycaenid butterfly Jalmenus evagoras and its attendant ants. Behavioral Ecology and Sociobiology, 21, 237-248. doi:10.1007/BF00292505

[14] Huxley, C.R and Cutler, D.F. (1991) Ant-plant interactions. Oxford University Press, New York.

[15] Morales, M.A. (2000) Mechanisms and density dependence of benefit in an ant-membracid mutualism. Ecology, 81, 482-489.

[16] Koptur, S. (1992) Interactions between insects and plants mediated by extrafloral nectaries. In: Bernays, E., Ed. CRC Series on Insect/Plant Interactions, Volume 4, CRC Press, Boca Raton, 85-132.

[17] Janzen, D.H. (1966) Coevolution of mutualism between ants and acacias in Central America. Evolution, 20, 249275. doi: $10.2307 / 2406628$

[18] Beattie, A.J. (1985) The evolutionary ecology of ant-plant mutualisms. Cambridge University Press, Cambridge. doi:10.1017/CBO9780511721878

[19] Ness, J.H. (2003) Catalpa bignonioides alters extrafloral nectar production after herbivory and attracts ant bodyguards. Oecologia, 134, 210-218.

[20] Vesprini, J.L., Galetto, L. and Bernardello, G. (2003) The beneficial effects of ants on the reproductive success of Dyckia floribunda (Bromeliaceae), an extrafloral nectary plant. Canadian Journal of Botany, 81, 24-27. doi:10.1139/b03-003

[21] Bugg, R.L. and Ellis, R.T. (1990) Insects associated with cover crops in Massachusetts. Biology, Agriculture and Horticulture, 7, 47-68.

[22] Kost, C. and Heil, M. (2005) Increased availability of extrafloral nectar reduces herbivory in Lima bean plants (Phaseolus lunatus, Fabaceae). Basic and Applied Ecology, 6, 237-248. doi:10.1016/j.baae.2004.11.002

[23] Wagner, D. and Kay, A. (2002) Do extrafloral nectaries distract ants from visiting flowers? An experimental test of an overlooked hypothesis. Evolutionary Ecology Research, 4, 293-305.

[24] Rosenweig, M.L. (2002). The distraction hypothesis depends on relatively cheap extrafloral nectaries. Evolutionary Ecology Research, 4, 307-311.

[25] Bentley, B.L. (1977) Extrafloral nectaries and protection by pugnacious bodyguards. Annual Review of Ecology and Systematics, 8, 407-427. doi:10.1146/annurev.es.08.110177.002203

[26] Elias T.S. (1983). Extrafloral nectaries: Their structure and distribution. In: Bentley, B.L. and Elias, T.S., Eds. The Biology of Nectaries, Columbia University Press, New York, 174-203.

[27] Heil, M., Fiala, B., Baumann, B. and Linsenmair, K.E. (2000) Temporal, spatial and biotic variations in extrafloral nectar secretion by Macaranga tanarius. Functional Ecology, 14, 749-757. doi:10.1046/j.1365-2435.2000.00480.x

[28] Heil, M., Hilpert, A., Fiala, B. and Linsenmair, K.E. (2001) Nutrient availability and indirect (biotic) defence in a Malaysian ant-plant. Oecologia, 126, 404-408.

\section{doi: $10.1007 / \mathrm{s} 004420000534$}

[29] Doak, P., Wagner, D. and Watson, A. (2007) Variable extrafloral nectary expression and its consequences in quaking aspen. Canadian Journal of Botany, 85, 1-9. doi:10.1139/b06-137

[30] Agrawal, A.A. and Rutter, M.T. (1998) Dynamic antiherbivore defense in ant-plants: The role of induced responses. Oikos, 83, 227-236. doi:10.2307/3546834

[31] Heil, M. and McKey, D. (2003) Protective ant-plant interactions as model systems in ecological and evolutionary research. Annual Review of Ecology, Evolution, and Systematics, 34, 425-453.

doi:10.1146/annurev.ecolsys.34.011802.132410

[32] Mondor, E.B. and Addicott, J.F. (2003) Conspicuous extrafloral nectaries are inducible in Vicia faba. Ecology Letters, 6, 495-497. doi:10.1046/j.1461-0248.2003.00457.x

[33] Mondor, E.B., Tremblay, M.N. and Messing, R.H. (2006) Extrafloral nectary phenotypic plasticity is damage- and resource-dependent in Vicia faba. Biology Letters, 2, 583585. doi:10.1098/rsbl.2006.0527

[34] Jaber, L.R. and Vidal, S. (2009) Interactions between an endophytic fungus, aphids and extrafloral nectaries: Do endphytes induce extrafloral-mediated defenses in Vicia faba? Functional Ecology, 23, 707-714. doi:10.1111/j.1365-2435.2009.01554.x

[35] Pulice, C.E. and Packer, A.A. (2008) Simulated herbivory induces extrafloral nectary production in Prunus avium. Functional Ecology, 22, 801-807. doi:10.1111/j.1365-2435.2008.01440.x

[36] Wackers, F.L. and Wunderlin, R. (1999) Induction of cotton extrafloral nectar production in response to herbivory does not require a herbivore-specific elicitor. Entomologia Experimentalis et Applicata, 91, 149-154. doi:10.1046/j.1570-7458.1999.00477.x

[37] Paiva, E.A.S., Buono, R.A. and Delgado, M.N. (2007) Distribution and structural aspects of extrafloral nectaries in Cedrela fissilis (Meliaceae). Flora-Morphology, Distribution, Functional Ecology of Plants, 202, 455-461. doi:10.1016/j.flora.2006.11.001

[38] Laird, R.A. and Addicott, J.F. (2007). Arbuscular mycorrhizal fungi reduce the construction of extrafloral nectaries in Vicia faba. Oecologia, 152, 541-551. doi:10.1007/s00442-007-0676-4

[39] Erith, A.G. (1930) The inheritance of colour, size, and form of seeds, and of flower colour in Vicia faba L. Genetica, 12, 477-510. doi:10.1007/BF01486760

[40] Ingels, C.A. (1998) Cover cropping in vineyards: A grower's handbook. University of California, Oakland.

[41] Koptur, S. (1989) Is extrafloral nectar production an inducible defense? In: Bock, J.H. and Linhart, Y.B., Eds., The Evolutionary Ecology of Plants, Westview, Boulder, 323-339.

[42] Katayama, N. and Suzuki, N. (2004) Role of extrafloral nectaries of Vicia faba in attraction of ants and herbivore exclusion by ants. Entomological Science, 7, 119-124. doi:10.1111/j.1479-8298.2004.00057.x

[43] SAS Institute Inc. (2008) JMP ${ }^{\circledR}$, version 8.0. Cary. 
[44] Tiffin, P. and Inouye, B. (2000) Measuring tolerance to herbivory: Accuracy and precision of estimates made using natural versus imposed damage. Evolution, 54, 10241029.

[45] Heil, M. (2009) Damaged-self recognition in plant herbivore defence. Trends in Plant Science, 14, 356-363. doi:10.1016/j.tplants.2009.04.002

[46] Quinn, G. and Keough, M. (2002) Experimental design and data analysis for biologists. Cambridge University Press, Cambridge. doi:10.1017/CBO9780511806384

[47] Koptur, S. Rico-Gray, V. and Palacios-Rios, M. (1998) Ant protection of the nectaried fern Polypodium plebeium in central Mexico. American Journal of Botany, 85, 736739. doi: $10.2307 / 2446544$

[48] O'Dowd, D.J. (1979) Foliar nectar production and ant activity on a neotropical tree, Ochroma pyramidale. Oecologia, 43, 233-248. doi:10.1007/BF00344773

[49] Southwick, E.E. (1984) Photosynthate allocation to floral nectar a neglected energy investment. Ecology, 65, 17751779. doi: $10.2307 / 1937773$

[50] Pyke, G.H. (1991) What does it cost a plant to produce floral nectar? Nature, 350, 58-59. doi:10.1038/350058a0

[51] Radhika, V., Kost, C., Mithofer, A. and Boland, W. (2010) Regulation of extrafloral nectar secretion by jasmonates in lima bean is light dependent. Proceedings of the National Academy of Sciences of the USA, 107, 1722817233. doi:10.1073/pnas.1009007107

[52] Zangerl, A.R. and Bazzaz, F.A. (1992) Theory and pattern in plant defense allocation. In: Fritz, R. and Simms, E.L., Eds., Plant Resistance to Herbivores and Pathogens, Uninversity of Chicago Press, Chicago, 363-392.

[53] Cohen, D. (1994) Modelling the coexistence of annual and perennial plants in temporally varying environments. Plant Species Biology, 9, 1-10. doi:10.1111/j.1442-1984.1994.tb00075.x

[54] Wackers, F.L., Zuber, D., Wunderlin, R. and Keller, F. (2001) The effect of herbivory on temporal and spatial dynamics of foliar nectar production in cotton and castor. Annals of Botany, 87, 365-370. doi:10.1006/anbo.2000.1342

[55] McNaughton, S.J. (1983) Compensatory plant growth as a response to herbivory. Oikos, 40, 329-336. doi: $10.2307 / 3544305$
[56] Trumble, J.T., Kolodny-Hirsch, D.M. and Ting, I.P. (1993) Plant compensation for arthropod herbivory. Annual Review of Entomology, 38, 93-119. doi:10.1146/annurev.en.38.010193.000521

[57] Bronstein, J.L., Alarcon, R. and Geber, M. (2006) The evolution of plant-insect mutualisms. New Phytologist, 172, 412-428. doi:10.1111/j.1469-8137.2006.01864.x

[58] Stephenson, A.G. (1982) The role of the extrafloral nectaries of Catalpa speciosa in limiting herbivory and increasing fruit production. Ecology, 63, 663-669. doi: $10.2307 / 1936786$

[59] De la Fuente, M.A.S. and Marquis, R.J. (1999) The role of ant-tended extrafloral nectaries in the protection and benefit of a Neotropical rainforest tree. Oecologia, 118, 192-202. doi: $10.1007 / \mathrm{s} 004420050718$

[60] Bugg, R.L., Ellis, R.T. and Carlson, R.W. (1989) Ichneumonidae (Hymenoptera) using extrafloral nectar of faba bean (Vicia faba L., Fabaceae) in Massachusetts. Biological Agriculture and Horticulture, 6, 107-114. doi:10.1080/01448765.1989.9754509

[61] Limburg, D.D. and Rosenheim, J.A. (2001) Extrafloral nectar consumption and its influence on survival and development of an omnivorous predator, larval Chrysoperla plorabunda (Neuroptera: Chrysopidae). Environmental Entomology, 30, 595-604. doi:10.1603/0046-225X-30.3.595

[62] Rose, U.S.R., Lewis, J. and Tumlinson, J.H. (2006) Extrafloral nectar from cotton (Gossypium hirsutum) as a food source for parasitic wasps. Functional Ecology, 20, 67-74. doi:10.1111/j.1365-2435.2006.01071.x

[63] Bronstein, J.L. (1994) Conditional outcomes in mutualistic interactions. Trends in Ecology and Evolution, 9, 214217. doi:10.1016/0169-5347(94)90246-1

[64] Thompson, J.N. (2005) The geographic mosaic of coevolution. University of Chicago Press, Chicago.

[65] Chamberlain, S.A. and Holland, J.N. (2009) Quantitative synthesis of context-dependency in ant-plant protection mutualisms. Ecology, 90, 2384-2392. doi:10.1890/08-1490.1

[66] Rutter, M.T. and Rausher, M.D. (2004) Natural selection on extrafloral nectar production in Chamaecrista fasciulata: The costs and benefits of a mutualism trait. Evolution, 58, 2657-2668. 